\title{
Effect of Casting Conditions on Some Mechanical Properties of Cobalt-Base Alloys
}

KAMAL ASGAR and FLOYD A. PEYTON

University of Michigan, School of Dentistry, Ann Arbor, Michigan

The casting of cobalt-base alloys in dentistry is comparatively new in relation to the casting of gold alloys and other restorative procedures. It has been less than thirty years since these alloys were introduced to dentistry, but each year they have become more popular. A survey of the choice of dental alloys for removable partial dentures conducted by Lane ${ }^{1}$ in 1949 showed that five times as many removable partial dentures were cast of the cobalt-base alloys as of gold alloys. Today this ratio may be even higher, since cobalt-base alloys are the choice of many dentists and laboratory technicians.

Unfortunately, even with such a high demand for this type of alloy in dentistry, little is known by the profession about the physical and mechanical properties of the alloy or about its basic nature. Similar alloys of cobalt are widely used in industry at high temperatures, and consequently more work is done and reported with this type of alloy used at high temperatures than at room temperature. Although acceptable dental techniques for casting these alloys are available, a completely dependable, accurate, and easy-to-apply technique has not yet been developed. Such a technique probably cannot be developed until more is known about the basic nature of these alloys and about the effect of variations in casting procedures upon their properties.

The purpose of this study was to determine the physical properties of cobalt-base alloys and to relate these properties to the microstructure, as well as to observe the influence of casting variables on both microstructure and physical properties. In this way the most acceptable casting practice can be selected which is revealed by both physical tests and microstructure.

\section{MATERIALS AND METHODS}

Preparation of specimens.-The size of the specimens in this study was patterned after a previous study conducted by Bush, Ingersoll, and Peyton at the University of Michigan School of Dentistry. ${ }^{2}$ The A.D.A. Specification No. 14 for the dental chromium-cobalt alloys ${ }^{3}$ also employs the same dimensions for the tensile test samples.

The test bar was $1 \frac{3}{8}$ inches in length, $0.09 \pm 0.01$ inch in diameter, and threaded at the ends with 12-24 threads. The size and shape of the test bars are shown in Figure 1. For the sake of convenience, the dimensions of the test bars were machined into a

This study was supported by a grant from the Office of Naval Research, Contract No. NR-180-360, to the University of Michigan, School of Dentistry.

This report represents a portion of a thesis submitted in partial fulfilment by Kamal Asgar for the degree of Doctor of Philosophy, H. H. Rackham School of Graduate Studies, University of Michigan.

Received for publication April 11, 1960; revised by authors August 18, 1960. 
split brass mold, and, by means of a hydraulic wax injector, the molten wax was squirted into the brass mold. After a short time, the wax in the brass mold was solidified, the two blocks were separated, and the wax patterns were removed. The wax pattern and manner of spruing are shown in Figure 2.

In this study a phosphate-bonded investment was used.* The wax patterns were

* Ransom and Randolph's investment No. 711 was used.

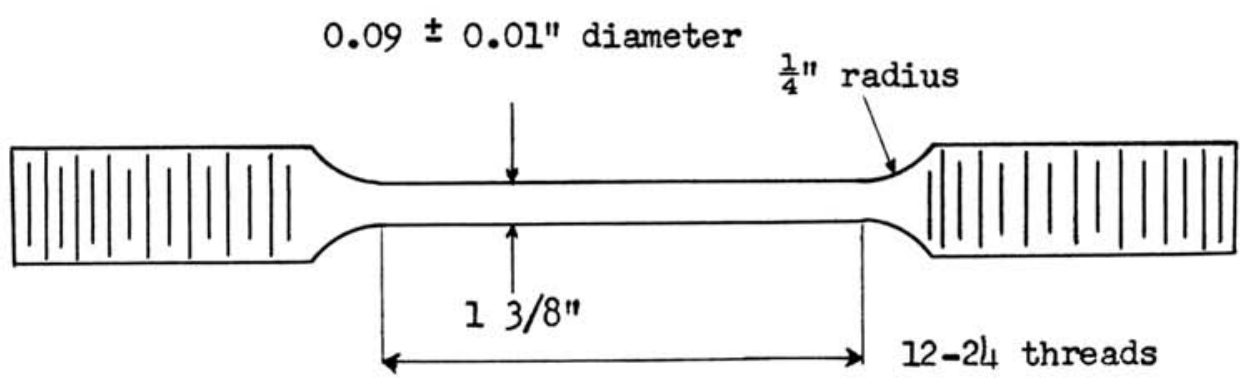

Fig. 1.-Dimensions of test bars

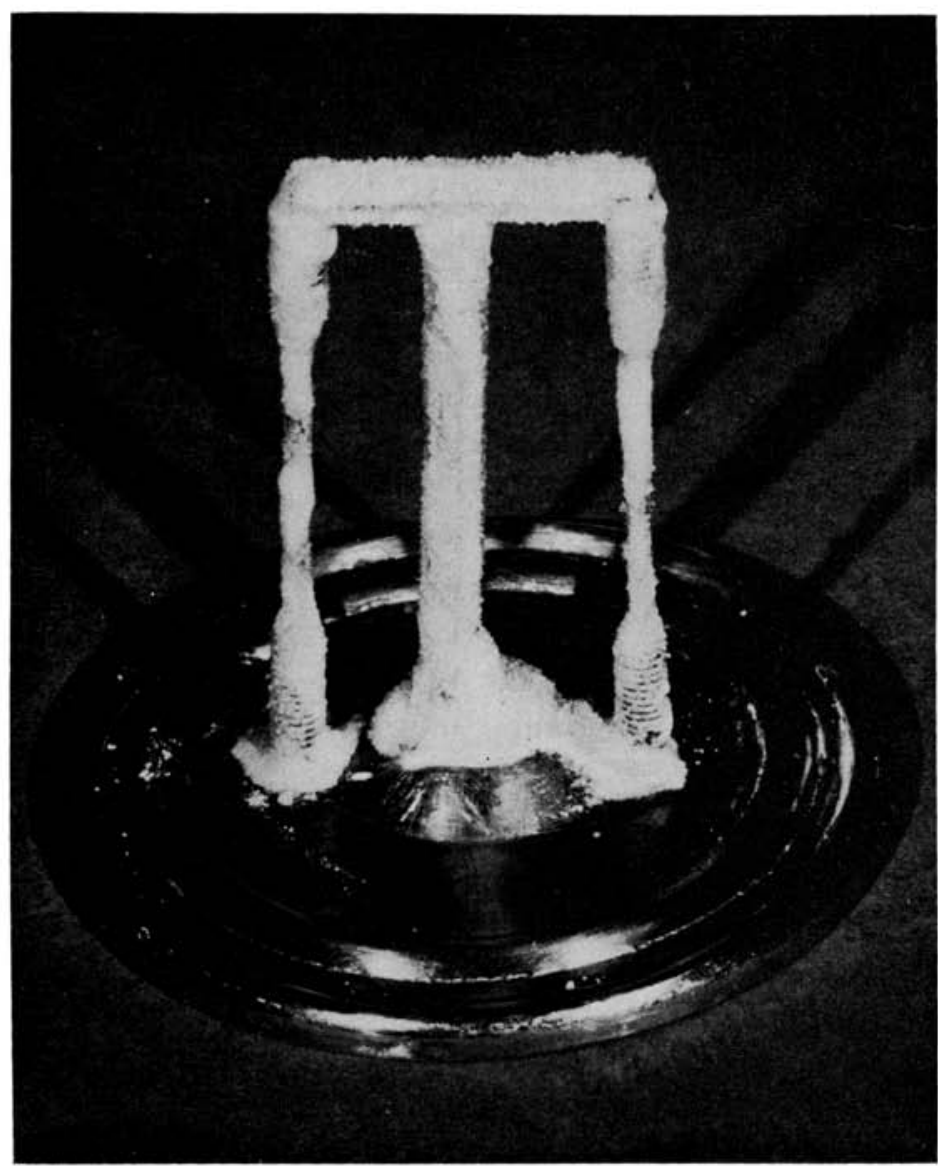

Fic. 2.-Manner of spruing wax pattern 
coated with an organic silicate, and a phosphate-bonded investment was used for backing up the precoat. In this study the dimensions of the casting were not important; therefore, the expansion of the investment received little attention. This investment was selected because it produces a clean surface and is relatively inexpensive.

The metal was melted electrolytically, and the temperature of the molten metal in each melt was checked by means of an optical pyrometer.* By having the optical pyrometer mounted on the casting machine, it was necessary to focus the pyrometer only once to direct it properly to cover the field of the crucible. This casting machine is shown in Figure 3, with an optical pyrometer mounted in position. After the casting was completed, the mold was left to cool to room temperature in air. The mold was then broken open and the casting recovered. By means of a sand-blasting unit, the investment particles were removed, and the cast metal piece cleaned. The test bars then were cut off and tested for mechanical properties.

Methods of mechanical testing.- The diameter of each test bar was measured with

*William's Inductocast unit was used for melting and casting of the metal, whereas Leeds and Northrup optical pyrometer was used to check the temperature of each melt.

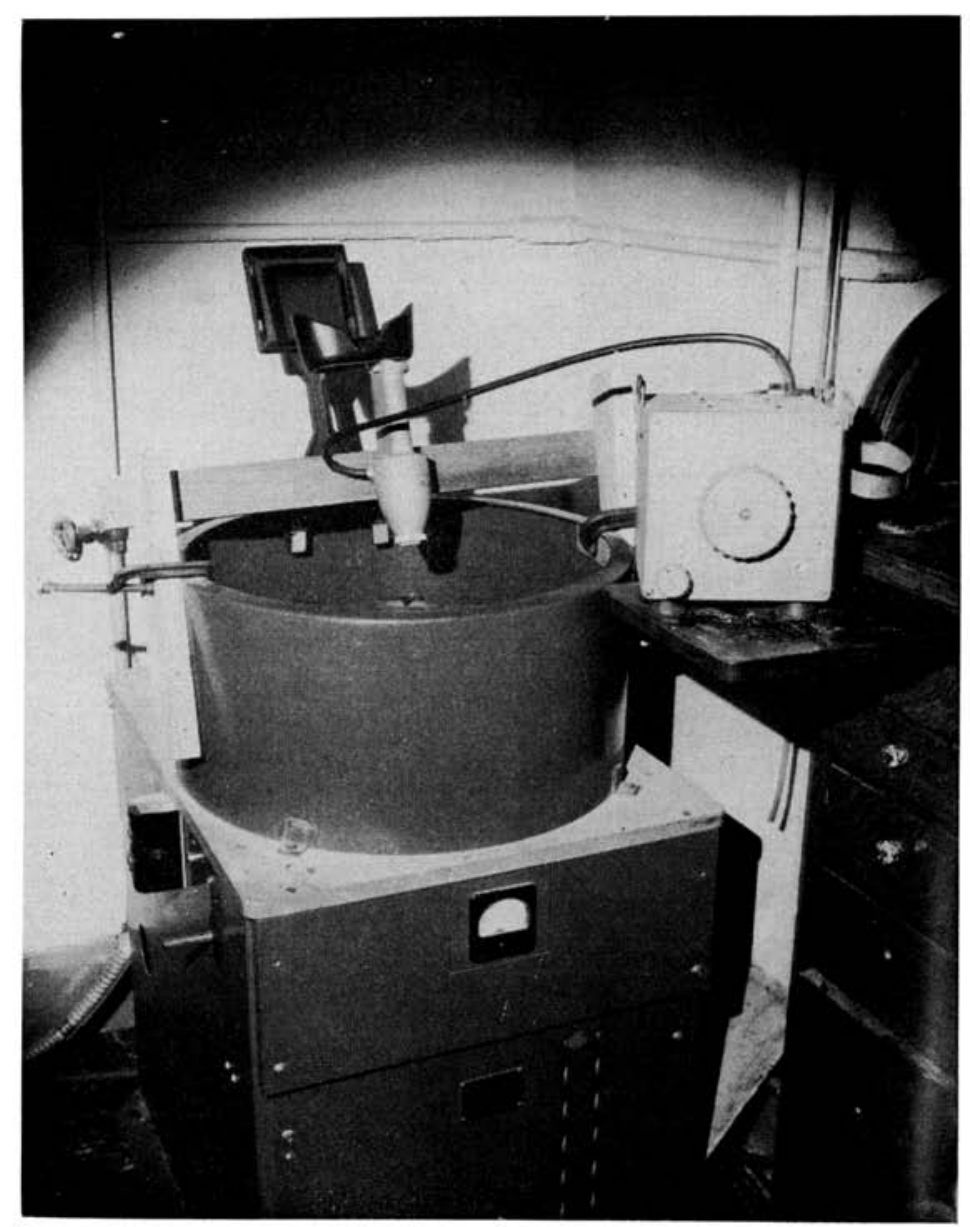

FIG. 3.-Williams casting machine and optical pyrometer 
a micrometer, and the values recorded. In order to obtain values for elongation, a distance close to 1 inch was marked on the specimens. By means of a traveling microscope, the distance between these two marks was measured to a hundredth of a millimeter. After the fracture, the test bars were placed as close together as possible, the dimensions between the two marks measured, and the percentage of elongation of the test bars calculated.

The specimens were tested by means of a tensile testing machine employing a head speed of 0.02 inch per minute. To obtain the strain on the sample introduced by the stress, either optical strain gauges or $3 \mathrm{M}$-extensometer was used.* After fracturing and measuring the distance between the two marks for the elongation values, the fractured pieces were mounted in a plastic type of material for metallographic examination. Half of each test bar was mounted and polished through different grades of papers and polishing wheels. The specimens were then etched to reveal their microstructure. In this way the microstructure of specimens with known physical properties was studied. The results of the microstructure studies are being reported separately. ${ }^{4}$

Casting procedure.-Stellite 21 was chosen as a cobalt-base alloy to be used throughout this study. The metal is typical of cobalt-base alloys and resembles closely those high-melting alloys used in dentistry. Since this study is basic in nature, probably similar results, with some minor modifications, can be expected from any one of the alloys of the group designed for dental application. The chemical analysis of Stellite 21 alloy used in this study was carried on, and the results were as follows: chromium, 27.44 per cent; molybdenum, 5.50 per cent; nickel, 2.50 per cent; manganese, 0.64 per cent; iron, 1.74 per cent; carbon 0.25 per cent; silicon, 0.62 per cent; and the balance cobalt.

The following casting conditions were studied: (1) molten metal heated to $2,600^{\circ} \mathrm{F}$., then cast into a mold of $1,600^{\circ} \mathrm{F}$. and allowed to cool on the bench to room temperature; (2) molten metal heated to $2,600^{\circ} \mathrm{F}$., cast into a mold of $1,300^{\circ} \mathrm{F}$. and bench-cooled; (3) molten metal heated to $2,800^{\circ} \mathrm{F}$, then cast into a mold of $1,600^{\circ} \mathrm{F}$., and bench-cooled; and (4) under condition like 1 , the metal was heated to $2,600^{\circ} \mathrm{F}$., cast into the mold at $1,600^{\circ} \mathrm{F}$, and bench cooled, after which the castings were heat-treated by placing them in an oven of $1,600^{\circ} \mathrm{F}$. for 1 hour and quenching in water.

Under each one of the above-mentioned four conditions, 20 casting were made. These castings were of the regular size indicated in Figure 1, with a length of $1 \frac{3}{8}$ inches and a diameter of $0.090 \pm 0.01$ inch. Some more castings were made with different specimen lengths. In varying the length of the test bars, four different lengths were arbitrarily chosen: $1 \frac{1}{4}, \frac{3}{8}, \frac{1}{4}$, and $\frac{1}{8}$ inches. Clusters of four test bars, one of each length, were made and attached to one sprue. In this way, all four sizes in the cluster were cast at the same time from one melt. In all these clusters, the metal temperature was $2,600^{\circ} \mathrm{F}$, and the mold temperature $1,600^{\circ} \mathrm{F}$. A total of five clusters was cast in this manner. These series are represented in Table 1 as conditions 5, 6, 7, and 8 . Since the results obtained from condition 3 -i.e., metal at the temperature of $2,800^{\circ} \mathrm{F}$. cast into the mold at $1,600^{\circ} \mathrm{F}$.- showed some difference in values, 20 more specimens with still higher metal temperature were cast. In this series, the metal temperature

\footnotetext{
* Tuckerman optical gauges and Riehle $3 \mathrm{M}$-extensometer were used in this study.
} 
was $3,000^{\circ} \mathrm{F}$, and the mold temperature was $1,600^{\circ} \mathrm{F}$. This series is represented in Table 1 as condition 9 .

The nine different conditions studied are listed in Table 1 ; results are summarized and reported in Table 2. This table shows the ultimate tensile strength, yield strength, elongation, and modulus of elasticity values, as well as standard deviations and other values obtained from statistical evaluation of the data.

\section{RESULTS AND DISCUSSION}

Ultimate tensile strength.-As can be seen in Table 2 , the average ultimate tensile strength of samples cast at $2,600^{\circ} \mathrm{F}$. into a mold at $1,600^{\circ} \mathrm{F}$. and bench-cooled was $99,600 \mathrm{lb} / \mathrm{sq}$ in. When the metal was heated to $2,800^{\circ} \mathrm{F}$. and cast into a mold heated to $1,600^{\circ} \mathrm{F}$, the average ultimate tensile strength was $95,000 \mathrm{lb} / \mathrm{sq}$ in. Subsequent heat treatment of the samples cast at $2,600^{\circ} \mathrm{F}$. into a $1,600^{\circ} \mathrm{F}$. mold gave ultimate tensile values of $107,400 \mathrm{lb} / \mathrm{sq}$ in. Samples cast at $3,000^{\circ} \mathrm{F}$. into a mold at $1,600^{\circ} \mathrm{F}$.

TABLE 1

Casting Conditions

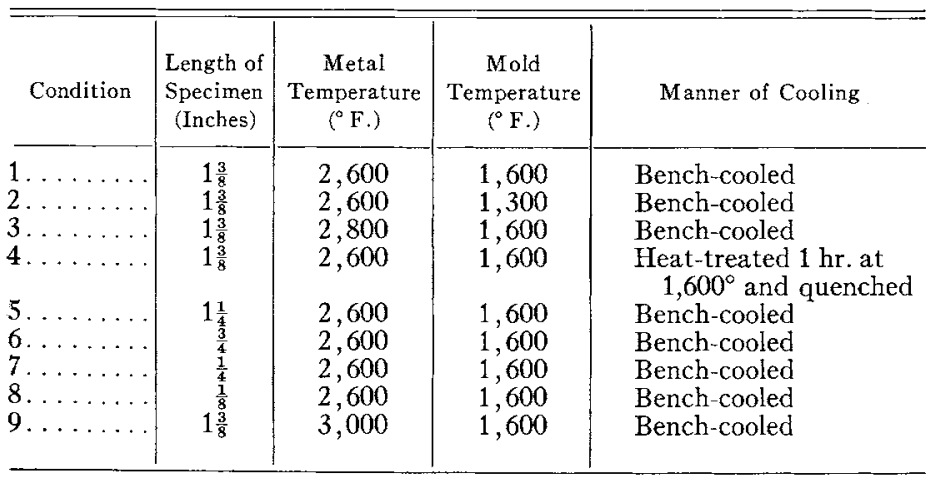

produced an average of $105,500 \mathrm{lb} / \mathrm{sq}$ in for the ultimate tensile values. In all these tests, conditions $1,2,3,4$, and 9 , the tensile test sample size was the same-1 13 inches -but the casting conditions varied. Although there was some difference in the ultimate tensile strength values obtained, ranging from approximately 96,000 to $107,000 \mathrm{lb} / \mathrm{sq}$ in, no single casting condition was superior to another, as indicated by the sizable standard deviation existing under each casting condition. Analysis of variance, which was used to distinguish any difference which might have existed between two sets of results, showed that the difference in values obtained for different test conditions was not significant.

The results of ultimate tensile strength tests on samples of different lengths cast as clusters (conditions 5, 6, 7, and 8) show that values for specimens within each cluster were more uniform than the values obtained from different clusters of test samples. The results from individual test samples of one cluster of four, for example, gave ultimate tensile strength values of $114,400,112,300,113,900$, and $112,200 \mathrm{lb} / \mathrm{sq}$ in for specimens with a length of $1 \frac{1}{4}, \frac{3}{4}, \frac{1}{4}$, and $\frac{1}{8}$ inches, respectively. A second cluster of test. samples gave ultimate tensile strength values of $102,000,104,000,90,900$, and 89,600 $\mathrm{lb} / \mathrm{sq}$ in, respectively, for the four lengths that were cast. All four specimens in this 
TABLE 2

Results of the Nine Casting Conditions

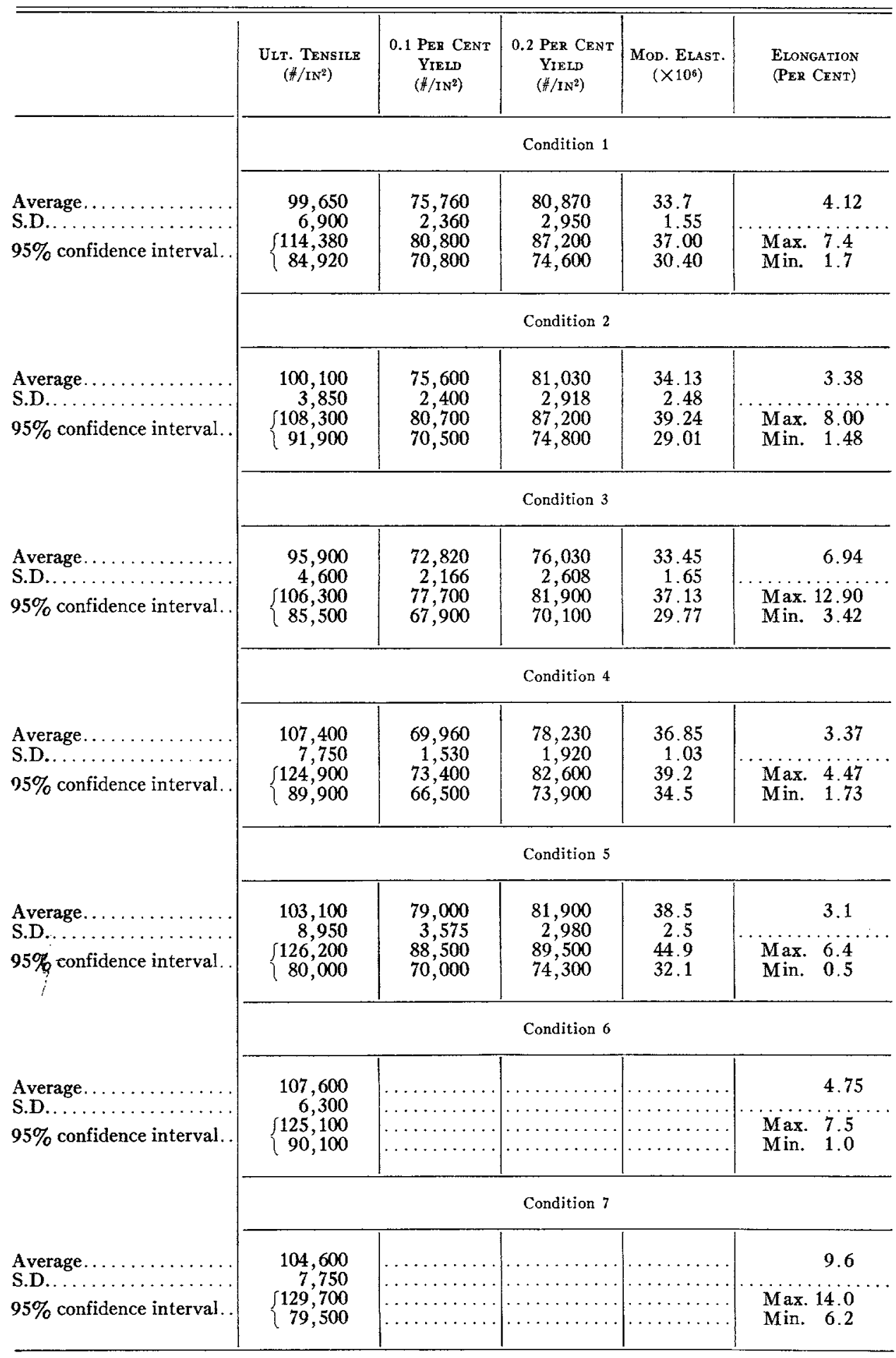


TABLE 2-Continued

\begin{tabular}{|c|c|c|c|c|c|}
\hline & $\begin{array}{l}\text { Uitr. TENSILE } \\
\left(\# \# / \mathrm{IN}^{2}\right)\end{array}$ & $\begin{array}{l}0.1 \text { PFR CENT } \\
\text { YIE ID } \\
\left(\# / I N^{2}\right)\end{array}$ & $\begin{array}{l}0.2 \text { PER CENT } \\
\text { YIELD } \\
\left(t / \mathbb{I N}^{2}\right)\end{array}$ & $\begin{array}{l}\text { MoD. EIAST. } \\
\quad\left(\times 10^{\ell}\right)\end{array}$ & $\begin{array}{l}\text { ELongatron } \\
\text { (PER Cent) }\end{array}$ \\
\hline \multirow{4}{*}{$\begin{array}{l}\text { Average } \ldots \ldots \ldots \ldots \\
\text { S.D. } \ldots \ldots \ldots \\
95 \% \text { confidence interval. }\end{array}$} & \multicolumn{5}{|c|}{ Condition 8} \\
\hline & \multirow{2}{*}{$\begin{array}{r}99,300 \\
8,000 \\
\left\{\begin{array}{r}119,900 \\
78,700\end{array}\right.\end{array}$} & \multirow{2}{*}{ 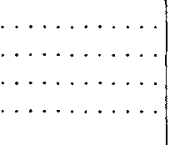 } & & & 11.3 \\
\hline & & & & & $\begin{array}{l}\text { Max. } 15.6 \\
\text { Min. } 8.2\end{array}$ \\
\hline & \multicolumn{5}{|c|}{ Condition 9} \\
\hline $\begin{array}{l}\text { Average } \ldots \ldots \\
\text { S.D. }{ }^{\prime} \ldots \\
\end{array}$ & \multirow{2}{*}{$\begin{array}{r}105,500 \\
4,950\end{array}$} & \multirow{2}{*}{$\begin{array}{r}77,100 \\
2,650 \\
83,900 \\
70,300\end{array}$} & \multirow{2}{*}{$\begin{array}{r}81,500 \\
3,240 \\
89,800 \\
73,200\end{array}$} & \multirow{2}{*}{$\begin{array}{r}36.1 \\
2.1 \\
41.4 \\
30.8\end{array}$} & 7.6 \\
\hline $95 \%$ confidence interval. & & & & & $\begin{array}{l}\text { Max. } 9.9 \\
\text { Min. } 5.6\end{array}$ \\
\hline
\end{tabular}

cluster had somewhat lower values than those of the first cluster, regardless of the sample length. Since results of only five clusters are available, however, it is not safe to draw definite conclusions, except that it appears probable that the unknown factors which cause variations in values of a cluster of samples are more effective than the specimen length on the ultimate tensile strength value.

The values obtained in this study were in close agreement with the values obtained by other investigators. Earnshaw ${ }^{5}$ reported, in 1956, the tensile strength values of some English-made cobalt-base alloys used in dentistry, in which the ultimate tensile strength of seven dental alloys tested had a range of $96,000-120,000 \mathrm{lb} / \mathrm{sq}$ in. His samples were 0.178 inch in diameter and 0.631 inch in length, which is different from the size used in this study. Earnshaw's values were reported as average values for each alloy type, and the individual variations in his results in each group were not discussed. More recently Taylor, Leibfritz, and $\operatorname{Alder}^{6}$ reported the ultimate tensile strength values of different dental alloys, with results varying from 85,000 to 108,000 $\mathrm{lb} / \mathrm{sq}$ in, and the standard deviation of different groups ranging from 4,000 to 12,000 $\mathrm{Ib} / \mathrm{sq}$ in. Taylor $e t$ al. used the same specimen size as was used in this study. Their results and the results obtained in this study for the ultimate tensile strength and its variations agree quite satisfactorily.

The values published by Haynes Stellite Company ${ }^{7}$ are given as an average value of $101,300 \mathrm{lb} / \mathrm{sq}$ in at room temperature for the ultimate tensile strength of Stellite 21. Although the test bars used by the Haynes Stellite Company had a diameter of 0.250 inch, whereas in this study they were only $0.090 \pm 0.01 \mathrm{inch}$, the values obtained for the ultimate tensile strength show close agreement.

It seems safe to assume, therefore, that the ultimate tensile strength of Stellite 21 is approximately $100,000 \mathrm{lb} / \mathrm{sq}$ in and that the size of the test specimen, as well as the casting conditions, may not have a significant effect on this property. Examination of the microstructure of different specimens revealed that even specimens containing a small amount of microporosity had an ultimate tensile strength as high as the specimens free of microporosity. It should be emphasized that this may possibly be true 
only for the ultimate tensile strength and not necessarily for other properties. As an example, photomicrographs of specimens Nos. 80 and 87 are shown in Figures 4 and 5. The ultimate tensile strengths of these specimens were both equal to $97,400 \mathrm{lb} / \mathrm{sq}$ in, even though the photomicrograph of specimen 87 shows some microporosity and that of 80 is free of porosity. The fact that specimens with some microporosity still show a comparatively high ultimate tensile strength may be due to the high modulus of elasticity and the high yield point of the alloy.

Yield strength and elastic modulus.-In order to obtain values of 0.1 per cent yield strength, 0.2 per cent yield strength, and modulus of elasticity, the relationship between stress and strain should be known. In general, no problem exists in obtaining the stress value on the sample at any instant during the testing. It is more difficult, however, to obtain the values for strain. Most values were obtained in this study by the use of the $3 \mathrm{M}$-extensometer, which was a non-averaging, magnetic snap-on type.

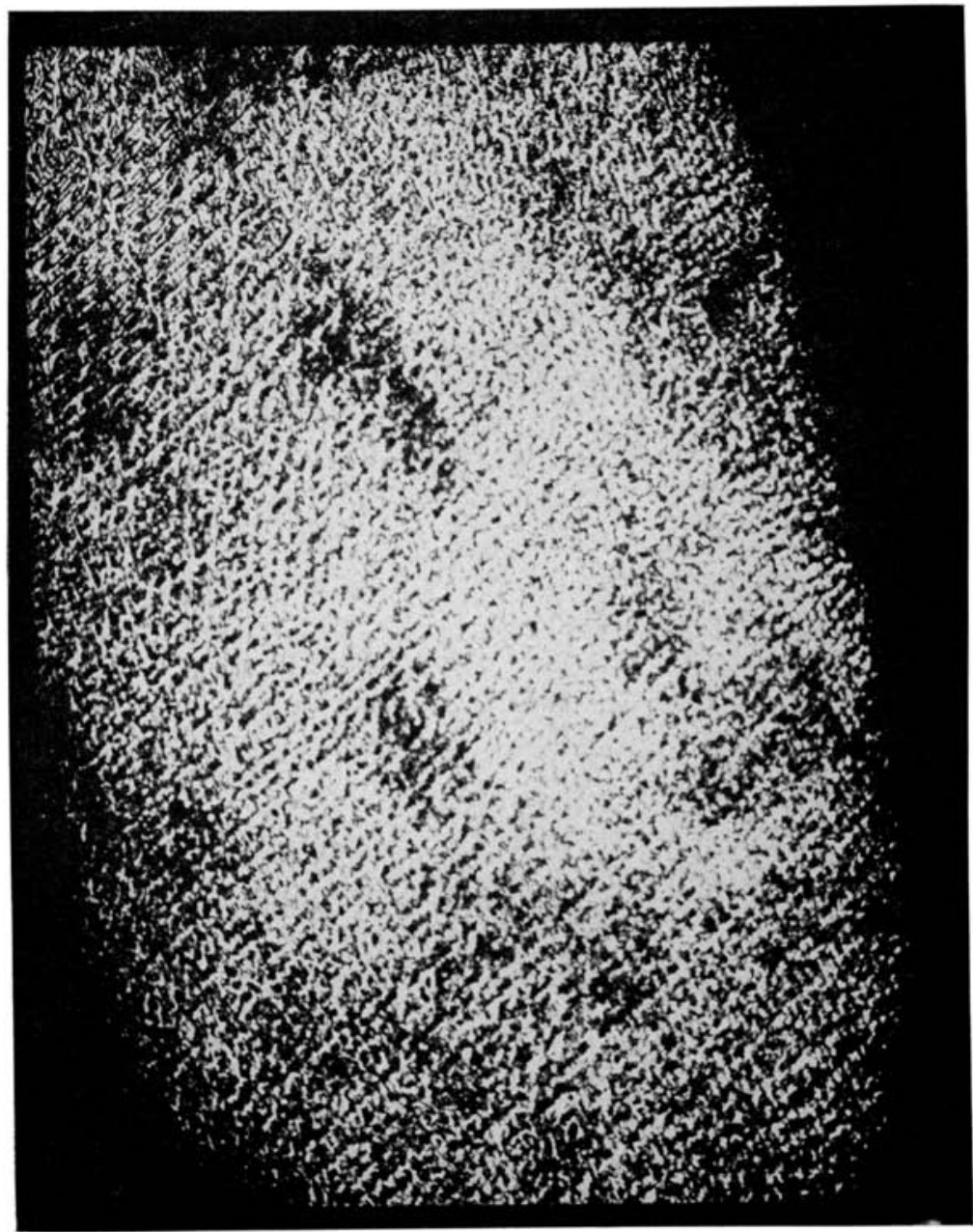

Fic. 4.-Microstructure of specimen 80. (Mag. $\times 85$.) 
This type of extensometer is quite convenient to use, but, since it is a non-averaging type and the samples were small, extreme care is necessary in preparing the samples.

The sensitivity of the 3M-extensometer and optical strain gauges and the validity of the results obtained were checked against a known sample. An aluminum specimen with a $\frac{1}{4}$-inch diameter and a modulus of elasticity known to be $10.6 \times 10^{6} \mathrm{lb} / \mathrm{sq}$ in was machined, and the results were obtained from optical strain gauges, as well as the $3 \mathrm{M}$-extensometer. The values obtained from optical strain gauges were $10.1 \times 10^{6}$ and $10.9 \times 10^{6} \mathrm{lb} / \mathrm{sq}$ in, with the average of $10.5 \times 10^{6} \mathrm{lb} / \mathrm{sq}$ in, and that obtained by the 3 M-extensometer was $10.6 \times 10^{6} \mathrm{lb} / \mathrm{sq}$ in. These results agree with the modulus of the elasticity of the aluminum sample.

The relation of strain to stress will vary if the specimen is bent during preparation or testing. This variation will increase if the diameter of the specimen is small or if the material tested has a low magnitude of strain. Both these factors were found to be

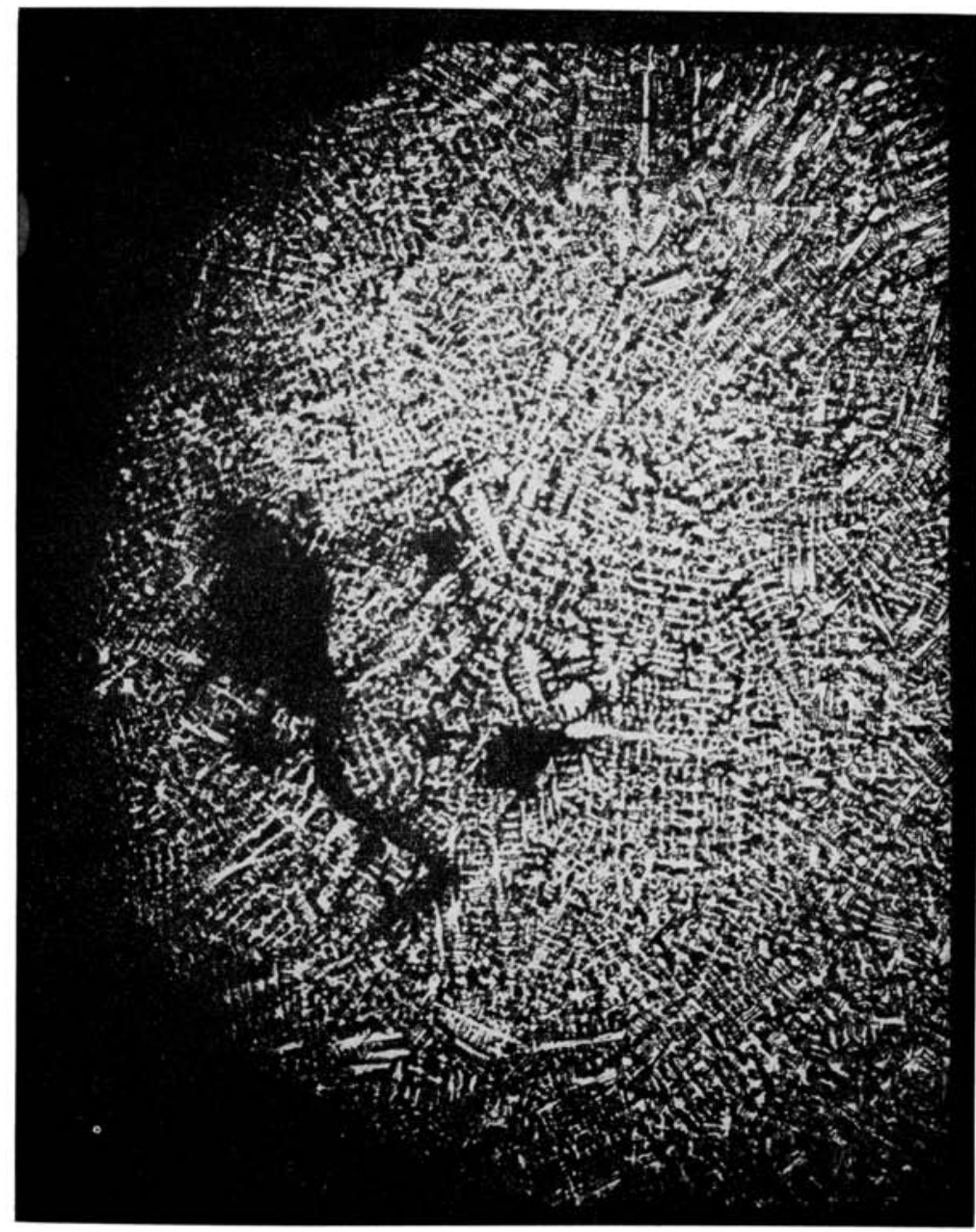

FIG. 5.-Microstructure of specimen 87. (Mag. $\times 85$. 
effective in obtaining the stress-strain relationship in this study. Templin ${ }^{8}$ has shown that surface conditions along the gauge length of the specimen, as well as the eccentric loading applied to the specimen, which results in a bending moment, may vary the stress-strain relationship considerably. Although extreme care was exercised in preparing the samples and performing the test, variation in the modulus of elasticity continued to be observed, a condition which is contrary to the principle that the modulus of elasticity of a material should be constant and not affected by heat treatment, variation of casting conditions, or other factors of manipulation. Theoretically, the only way to change the modulus of elasticity of an alloy is by altering its chemical composition. Consequently, the variation in the modulus of elasticity in this study should not be attributed to poor testing technique or the size of the sample. Similar results have been obtained by other investigators. Taylor et $a l^{6}{ }^{6}$ have reported their modulus of elasticity value to range from $28 \times 10^{6}$ to $31.0 \times 10^{6} \mathrm{lb} / \mathrm{sq}$ in for each alloy tested, and the standard deviation was reported as $2.5 \times 10^{6} \mathrm{lb} / \mathrm{sq}$ in. The results obtained for the modulus of elasticity by other investigators ${ }^{9}$ using specimens $\frac{1}{4}$ inch or $\frac{1}{2}$ inch in diameter have also shown similar variations. In this study the calculated standard deviation for different conditions varied from $1.03 \times 10^{6}$ to $2.5 \times 10^{6}$, with average values ranging from 33.45 to $38.5 \times 10^{6} \mathrm{lb} / \mathrm{sq}$ in.

It is possible to obtain 0.1 and 0.2 per cent yield strength values from the stressstrain curve. It is somewhat more convenient and practical to obtain the offset yield strength than the value for proportion limit. The values of 0.1 and 0.2 per cent yield strength obtained under condition 4 were somewhat lower than those obtained under other conditions. The 0.1 per cent yield strength of $75,000 \mathrm{lb} / \mathrm{sq}$ in or higher was obtained in other conditions, whereas the 0.1 per cent yield strength value for condition 4 averaged $69,960 \mathrm{lb} / \mathrm{sq}$ in. The yield strength of the alloy is important in practice, since it represents the value where permanent deformation takes place in the structure. If an alloy has a high modulus of elasticity but a low yield strength, it is not a proper alloy for partial dentures. Alloys used in partial dentures should have not only a high modulus of elasticity but also a high yield strength, so that permanent deformation of the cast piece does not take place easily. Griffiths ${ }^{10}$ points out that the minimum yield strength of cobalt-base alloys used in dentistry should be $70,000 \mathrm{lb} / \mathrm{sq}$ in.

Because of the short specimen size (less than 1 inch), the stress-strain relationship was not obtained for conditions 6,7 , and 8 , and, as a result, the 0.1 and 0.2 per cent yield strength and the modulus of elasticity are not reported for these test conditions.

Elongation.--One of the important properties of a dental alloy is its ductility, which in most cases is indicated as a percentage of elongation. In burnishing the gold inlays or in adjusting the clasps on partial dentures, the ductility of the cast pieces is most important. Both before initial insertion and after being in service for some time, partial denture clasps may need some adjustments, for which reason the ductility of the cast piece becomes an important property. The test specimen is marked along its length, and the distance between the two gauged marks is measured before and after the fracture. The change in the length of the specimen is reported on a percentage basis, as per cent of elongation, which gives some indication of the ductility of the material. This value was obtained for all specimens 
but for conditions 6,7 , and 8 and is reported in Table 2 . In contrast to the ultimate tensile strength values, this value varied from a very low value of 0.5 to as much as 12 per cent. The presence of microporosity had a definite effect on the per cent of elongation.

It was found that, in order for the castings of this alloy to have higher elongation values, not only should they be sound and free from microporosity but also their microstructure should be of a definite type. To clarify this statement, consider the physical properties as well as the microstructures of specimens 80 and 87 , which are shown in Figures 4 and 5. Both specimens were cast under the same conditions, and both registered an ultimate tensile strength of $97,400 \mathrm{lb} / \mathrm{sq}$ in, whereas the per cent of elongation of specimen 80 was 8.25 per cent, and that of specimen 87 was only 3.4 per cent. The microstructure of specimen 87 reveals the presence of some microporosities, whereas the microstructure of the specimen 80 was free of any porosities. These findings indicate that the presence of microporosities is an important factor in elongation values. Comparing the photomicrographs of specimens 51 and 58 shown in Figures 6 and 7, it is seen that, although both these specimens were cast under the same conditions, they possess different microstructures. Specimen 51 shows a very slight amount of microporosity and a 6.6 per cent elongation, whereas specimen 58, with no microporosity, had only 2.1 per cent elongation. This indicates that microstructure may be as significant in modifying the properties as is the microporosity. This part of the study is discussed in more detail in a separate publication. ${ }^{4}$

Examination of the results obtained from condition 3 reveals that, in general, the specimens of this group have relatively high elongation values. Specimens without microporosities showed as much as 12 per cent elongation, and the specimens with microporosities showed over 3 per cent elongation. In Table 2 the average values for the per cent of elongation, using the full length of the test samples as a gauge length, were $4.12,3.38,6.94,3.37$, and 7.6. The two higher values, 6.94 and 7.6 per cent, represent the metal casting temperatures of $2,800^{\circ} \mathrm{F}$. and $3,000^{\circ} \mathrm{F}$. cast into molds of $1,600^{\circ} \mathrm{F}$. When this metal was heated to $3,000^{\circ} \mathrm{F}$. and cast, the interaction between the surface of the metal and the mold material was great. Because of the reaction of metal with mold material, the surface condition of the cast pieces was poor and not acceptable in practical dental cases. At low metal temperatures such as $2,600^{\circ} \mathrm{F}$., the surfaces of the castings were clean, and there were no interphase reactions between the metal and the investment, but the average elongation was 3-4 per cent. At a metal temperature of $2,800^{\circ} \mathrm{F}$., the metal surface was not damaged; however, it was somewhat darker gray in color, and the average elongation was about 7 per cent. The reduction in a cross-sectional dimension (diameter) of a test sample cast at $2,800^{\circ} \mathrm{F}$, with an elongation of 7.25 per cent, is shown in Figure 8 . It can be seen from Figure 8 that the cobalt-base alloys, when cast under certain conditions, may possess higher elongation values than are usually known in dental castings.

The averages of the elongation values reported for conditions $5,6,7$, and 8 were $3.1,4.75,9.6$, and 11.3 per cent, respectively. These values were expected to be the same, since the mold and metal temperature for conditions $1,5,6,7$, and 8 were identical. It should be recalled that the lengths of the test samples for specimens 
whose results were reported in Table 2 under conditions 6,7 , and 8 were $\frac{3}{4}, \frac{1}{4}$, and $\frac{1}{8}$ inch but all had a diameter of 0.097 inch. The elongation took place mainly in the thin section of the specimen between the threads, and the per cent of elongation was calculated on this basis. It is well known that if the elongation of a sample is based on shorter gauge marks and if the fracture takes place between the marked gauges, the calculated per cent of elongation is much greater than if a longer gauge length is used. The higher elongation reported for these specimens was probably due to a shorter gauge length.

\section{SUMMARY AND CONCLUSIONS}

A total of 120 test specimens of Stellite 21 were cast under different casting conditions. The conditions were mainly changing metal temperature, altering the mold temperature, heat-treating the test specimens, as well as varying the length of the specimen. Tensile strength, 0.1 and 0.2 per cent yield strength, modulus of elasticity,

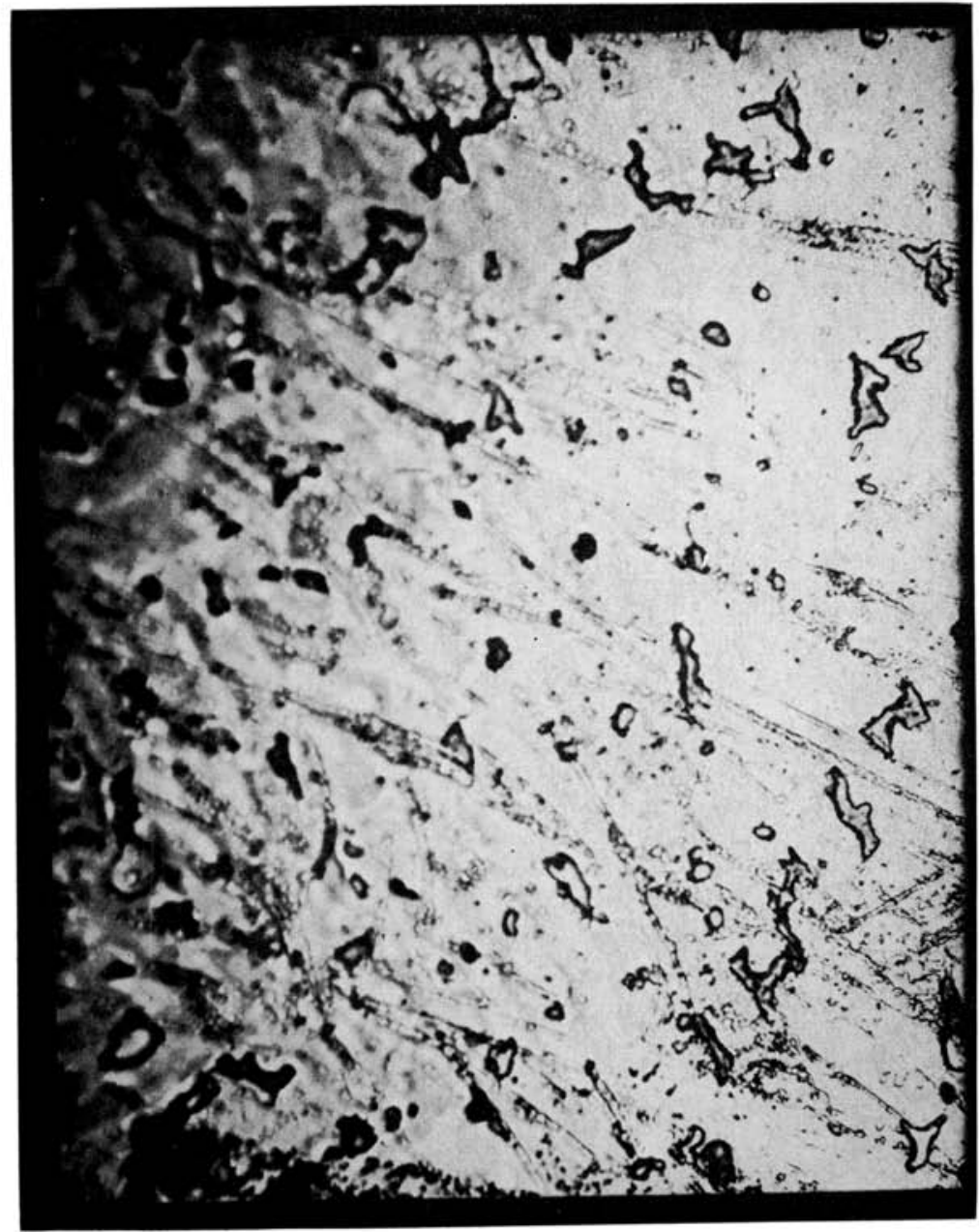

FIG. 6.-Microstructure of specimen 51. (Mag. $\times 800$.) 


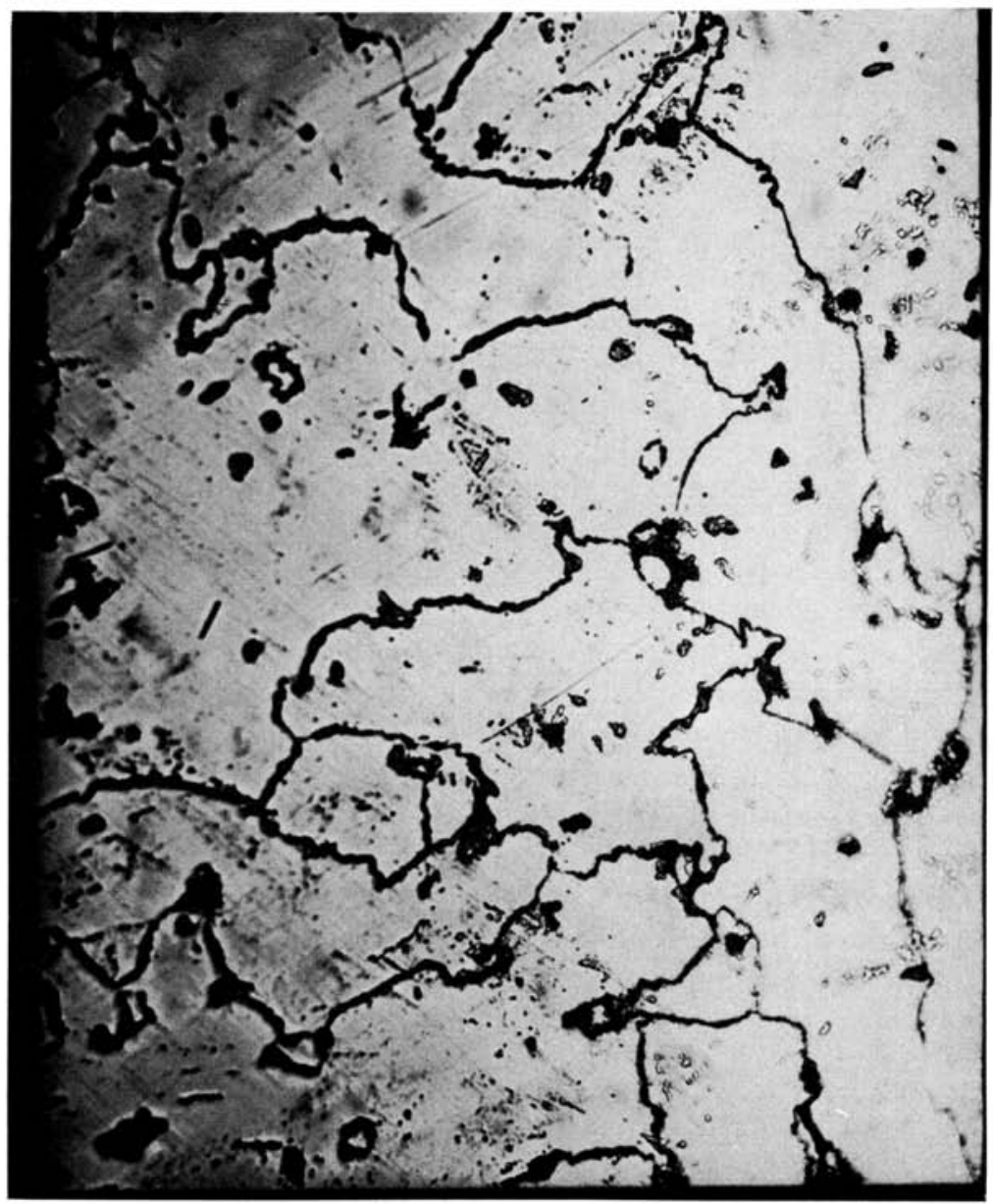

Fic. 7.-Microstructure of specimen 59. (Mag. $\times 800$.)

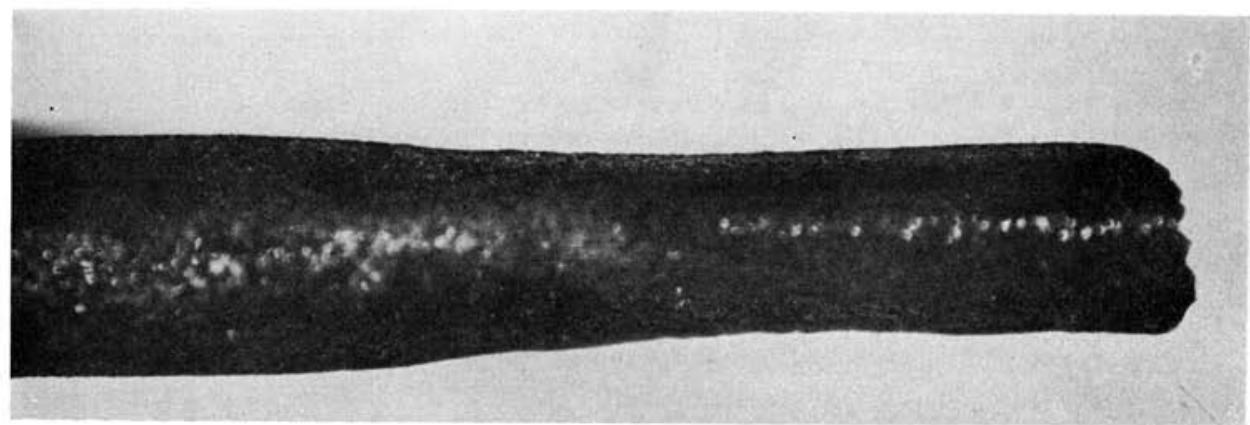

FIG. 8.-Reduction in cross-sectional area of the specimens with higher elongation values 
and per cent of elongation for the test bars were obtained. The results were statistically analyzed, and the average, standard of deviation, and 95 per cent confidence interval for each group were calculated. From the results of this study, the following statements may be drawn.

The ultimate tensile strength of Stellite 21 at room temperature was found to be approximately $100,000 \mathrm{lb} / \mathrm{sq}$ in, which varied little with a change in metal casting temperature, mold temperature, and the length of the test specimen.

The presence or absence of microporosities in the alloy did not change the ultimate tensile strength significantly. The presence of microporosities, as well as different types of microstructure in the specimens, has a significant effect on the elongation values obtained.

The values obtained for 0.1 per cent and 0.2 per cent yield strengths were more uniform than the ultimate tensile strength values.

The modulus of elasticity of Stellite 21 under testing conditions of this study varied between approximately 30 and $40 \times 10^{6} \mathrm{lb} / \mathrm{sq}$ in, with the typical value being $35 \times 10^{6} \mathrm{lb} / \mathrm{sq}$ in.

Specimens with metal casting temperatures of $2,800^{\circ} \mathrm{F}$. and $3,000^{\circ} \mathrm{F}$. yielded a higher per cent elongation than when a lower temperature was used. At $3,000^{\circ} \mathrm{F}$. metal casting temperature, however, the interphase reaction between the surface of the metal and the investment increased considerably, and, as a result, the surfaces of the cast pieces were damaged.

The chosen heat-treating cycle did not improve any of the prope is of the alloy and possibly harmed them. The surface appearance of the heat-treated pieces was somewhat inferior.

\section{REFERENCES}

1. LANE, J. R. A Survey of Dental Alloys, J.A.D.A., 39:441, 1949.

2. Buse, S. H., Ingersolr, C. H., and Peyton, F. A. The Effect of Section Size on the Mechanical Properties of Cast Chrome-Cobalt Dental Alloys. Navy Contract NG-ONR-232 Progress Report, School of Dentistry, University of Michigan, 1952.

3. Taylor, D. F., and Sweeney, W. T. A Proposed Specification for Dental Chromium-Cobalt Casting Alloys, J.A.D.A., 54:44, 1957.

4. Asgar, K., and Peyton, F. A. The Effect of the Microstructure on the Physical Properties of Chromium-Cobalt Alloys, J. D. Res., in press.

5. Earnshaw, R. Cobalt-Chromium Alloy in Dentistry, Brit. D. J., $101: 67,1956$.

6. Taylor, D. F., Leibrrita, W. A., and Alder, A. G. Physical Properties of Chromium-Cobalt Dental Alloys, J.A.D.A., 56:343, 1958.

7. Haynes Alloys for High-Temperature Service. Kokomo, Ind.: Haynes Stellite Co., a Division of Union Carbide and Carbon Co., Copyright 1950.

8. Templing, R. L. Effect of Size and Shape of Test Specimens on the Tensile Properties of Sheet Metals, A.S.T.M. Proc., 26:378, Part II, 1926.

9. "Heat-resistant Casting, by Subcommittee on Heat-resistant Castings." In T. Lyman (ed.), Metal Handbook, p. 570. Cleveland: Amer. Soc. Met., 1948.

10. Grifritus, E. S., and Casmman, W. D. Alloy Adapted for Prosthetic Articles. U.S. Patent $2,631,095$. March, 1953. 